\title{
Childhood Solid Neoplasm
}

National Cancer Institute

\section{Source}

National Cancer Institute. Childhood Solid Neoplasm. NCI Thesaurus. Code C9107.

A solid neoplasm (e.g., carcinoma, sarcoma) occurring in children. 